\title{
EFFECT OF MEASUREMENT METHOD AND MOISTURE CONTENT ON WHEAT KERNEL DENSITY MEASUREMENT
}

\author{
C. FANG and G. M. CAMPBELL \\ Satake Centre for Grain Process Engineering, Department of Chemical Engineering, UMIST, Manchester, UK
}

$\mathrm{W}$ heat kernel breakage is a critical factor in the flour milling process, and is affected by kernel density. Kernel density measurement is not routinely performed, and depends on the measurement technique used and the moisture content of the grains. This study compared currently available wet and dry methods based on gas displacement and liquid displacement (using water, water-ethanol mixtures and xylene) to determine the density of Hereward (hard) and Consort (soft) wheat kernels of different sizes and moisture contents. A gas pycnometer was used to measure the average density of a sample of wheat kernels, while a double cup system was used to measure individual kernel density by weighing kernels in air and immersed in liquid.

The hard wheat variety, Hereward, had kernels of slightly higher average density, with a narrower distribution, than the soft variety, Consort. Kernel density was independent of kernel size, while increasing moisture content decreased the measured kernel density. The dry technique using the gas pycnometer gave the highest kernel densities, followed by xylene immersion, with water immersion giving the lowest density values, lower than the dry technique by $6.2 \%$ for Hereward and $9.9 \%$ for Consort. This was attributed to the effect of surface tension effectively increasing the kernel volume measured by the wet method. Further investigations with water-ethanol mixtures of varying surface tension supported this.

The current trend in cereal quality testing is to measure distributions of single kernel physico-chemical parameters. The wet method allowed the measurement of the distribution of single kernel densities, but with poor accuracy due to surface tension; what is needed is a dry single kernel density method.

Keywords: wheat kernel density; hardness; surface tension; xylene; gas pycnometer.

\section{INTRODUCTION}

The process of milling wheat into flour is determined by the anatomical structure of the wheat kernel. Wheat kernels, like other cereals, contain nutritious starchy endosperm (to feed the germinating plant) surrounded by a protective coating of several botanically distinct layers known collectively as bran. The bran of some cereals, in particular rice, can be separated from the endosperm by simple abrasion, with the result that the endosperm of rice grains is eaten as intact particles. However, wheat (in common with barley, oats and rye) has an anatomical feature, the crease, in which the bran layers fold together into the centre of the grain ${ }^{1}$. While recent innovations such as the Satake PeriTec process ${ }^{2,3}$ have exploited abrasion of wheat grains prior to milling, ultimately to separate wheat bran from endosperm, the kernel must be broken open. This is achieved using counterrotating fluted rolls, which break the kernel open such that the bran particles tend to stay large while the endosperm particles are smaller, so that bran and endosperm can be separated based on size using plansifters. By using repeated roller milling and sifting in the 'gradual reduction process', highly efficient recovery of relatively pure endosperm material is achieved.

The gradual reduction process can be viewed as the evolution of the particle size distribution, starting with the initial breakage of the mixture of wheat kernels as they enter the process at the First Break rolls. Breakage of the wheat at this initial stage determines the particle size distribution produced and hence the flowrates of material through the various routes that comprise the remainder of the process. Breakage of individual kernels in roller milling is independent of the surrounding kernels ${ }^{4,5}$; each kernel breaks according to its own physico-chemical characteristics (size, shape, hardness, moisture content, protein content, density, etc.). The current trend in cereal quality testing is to measure distributions of these parameters ${ }^{6,7}$. Examples of commercial instruments include the Perten Single Kernel 
Characterization System (SKCS) ${ }^{6,8-11}$, which measures the mass, diameter, moisture content and hardness of each kernel in a sample, and the Satake Rice Image Analyser, which uses two orthogonal cameras to measure the length, width and thickness of individual grains.

Hardness is a widely used measure of wheat breakage patterns, which is measured using a range of approaches and instruments based on crushing force, time to grind or particle size produced ${ }^{12}$. It is quantified in the Perten SKCS by measuring the force profile during crushing of individual grains between a rotor and a crescent. The SKCS processes 300 kernels within 5 minutes, so is suitable for rapid acceptance testing of wheat on delivery to mills. Hardness, however, is not defined in a fundamental sense, such that relating hardness measurements to genetic and environmental influences, and to milling performance is not straightforward. Some fundamental studies of wheat hardness have been reported based on fracture mechanics approaches in well-defined geometries ${ }^{13,14}$. However, the heterogeneous structure and composition of the wheat kernel limits such studies.

It has been reported that hardness is correlated with kernel density, hard wheats tending to have higher average densities ${ }^{15,16}$. The advantage of density measurement is that it is a fundamental and unambiguous parameter with defined units. Nevertheless, its measurement has not been applied practically to characterization of wheat or other cereals. Bulk density measurements, based on weighing a container of known volume filled with wheat, have been widely used for many years, but the true density of individual kernels is harder to measure routinely.

Sharp ${ }^{17}$ reported that kernel size, moisture content, protein content and quality influence wheat kernel density. Pomeranz ${ }^{12}$ indicated that dense wheat kernels normally have a higher ratio of endosperm to non-endosperm components than do smaller, less dense kernels; this is potentially advantageous to millers in terms of yield of flour.

Peters and $\mathrm{Katz}^{18}$ used a density gradient column to determine the wheat density. The density gradient, which was provided by a solution of carbon tetrachloride and cyclohexane, ranged from 1.29 to $1.41 \mathrm{~g} \mathrm{~cm}^{-3}$. Knowing the density of the solution as a function of the height, the density of the kernel placed in the solution was measured. Based on this method, the distribution of the densities of individual wheat kernels was also measured. Dobraszczyk et al. ${ }^{16}$ used the same approach, their results suggesting soft wheats have lower densities and a broader distribution. They suggested a causative explanation for the relationship between density and hardness, that the air spaces in soft wheats that lower the density might act as stress concentration regions which aid kernel breakage, thereby also lowering the hardness of the kernel.

Chang ${ }^{19}$ used a gas pycnometer to measure wheat kernel density, and demonstrated that there are pore spaces inside wheat kernels by comparing the measured densities of ground kernel particles, wax coated kernels, and raw kernels. For the wheat variety used, the porosity of the kernels was between $3.6 \%$ and $7 \%$, and the percentage of the pore spaces inaccessible to gas was between $27 \%$ and $36 \%$ of all void spaces. In other words, approximately twothirds of pore spaces are connected to the surface of the kernel, which is accessible to the gas. The author also mentioned that liquids were probably not adequately suited for determining void spaces for most seed kernels due to surface tension. More recent work by Martin et al. ${ }^{20}$ used a micropycnometer based on liquid displacement to measure the kernel volume. The liquid was a low surface wetting manometer oil. The results showed that the densities of healthy kernels, scab-damaged kernels and sproutdamaged kernels were significantly different. This study also found no relationship between SKCS hardness and density of individual kernels within a wheat variety, although this does not preclude a relationship between varieties, as reported by other workers ${ }^{15,16}$.

The methods used by previous workers to investigate wheat kernel density can be classified into two categories: gas displacement and liquid displacement methods. The above studies showed preferences in using low surface tension liquids or gases for determining the kernel density, to avoid the problems caused by the pore spaces on wheat kernel surfaces. However, the effect of the surface tension on the kernel density measurement has not been quantified in previous research.

The purpose of this study was to compare two methods of measuring the true density of wheat, and to investigate factors regarding the methods used (wet versus dry and the effect of liquid type and surface tension on the wet method) and of the kernels themselves (wheat variety, kernel size and moisture content). The two methods were gas displacement using an Accupyc gas pycnometer, and liquid displacement using a double cup density determination kit supplied by Precisa.

\section{MATERIALS AND METHODS}

\section{Wheat Samples}

Two varieties of wheat were used in this study, one hard wheat, Hereward (14.6\% protein $\mathrm{db})$, and one soft wheat, Consort (10.6\% protein $\mathrm{db}$ ), from the 1999 UK harvest. Only sound and healthy wheat kernels were used in this study. The distributions of kernel size, mass, moisture and hardness were determined for each variety using the Perten SKCS Model 4100 (Perten Instruments AB, Sweden).

\section{Accupyc Gas Pycnometer}

The gas pycnometer (Accupyc 1305, Micromeritics Instrument Corporation, USA) uses gas displacement to measure the volume of powders, granules or other solid objects, or of liquids. The measurement of the volume is done by observing the reduction of gas capacity in the sample chamber caused by the presence of the sample, by measuring the pressure drop with and without sample when the sample chamber is connected to an expansion chamber, as shown in Figure 1. The sample of which the volume is to be measured is placed in the sample chamber and the expansion valve is closed. Then the fill valve is opened and the sample chamber is charged to a relative pressure $P_{1}$. After recording the pressure, the expansion valve is opened and the original gas in the sample chamber is released to fill both the sample chamber and the expansion chamber. Consequently, the relative pressure of the sample chamber is reduced to $P_{2}$. According to both readings, the volume of 
the sample can be calculated by the following equation ${ }^{21}$, based on the ideal gas law:

$$
V_{\mathrm{s}}=V_{\mathrm{c}}-\frac{V_{\mathrm{e}}}{\frac{P_{1}}{P_{2}}-1}
$$

where $V_{s}$ is the volume of the sample, $V_{\mathrm{c}}$ is the volume of the empty, closed sample chamber, and $V_{\mathrm{e}}$ is the volume of the expansion chamber. $V_{\mathrm{c}}$ and $V_{\mathrm{e}}$ are determined by calibration. Knowing the mass of the sample, $m$, the density is determined by:

$$
\rho_{\mathrm{s}}=\frac{m}{V_{\mathrm{s}}}
$$

Ideally, helium provides the best accuracy because it follows the ideal gas law closely. Nitrogen was used in this study because the deviation is entirely negligible where the temperatures and the pressures are not far removed from ambient $^{22}$.

Samples cups of various sizes $\left(5,35,150 \mathrm{~cm}^{3}\right)$ can be used with the Accupyc 1305. For these studies the $5 \mathrm{~cm}^{3}$ cup was used, with the sample chamber filled to its full capacity but avoiding compression of the sample when the lid was screwed down. The Accupyc could only be used to determine the average density of a sample of numerous grains, normally in the range 50-95 kernels; its accuracy does not allow determination of individual kernel density.

\section{Precisa Density Determination Kit}

This method uses a precision balance in conjunction with a density determination set supplied by Precisa Balances Ltd, UK. Wheat kernels were weighed individually in air to $0.1 \mathrm{mg}$ using a Precisa 125A balance (Precisa Balances Ltd., UK), then immersed in a liquid of known density using a double cup system, and weighed again. From the difference in weights, the density was calculated using:

$$
\rho=\frac{m_{\text {air }}}{m_{\text {air }}-m_{\text {liquid }}} \rho_{1}
$$

where $\rho$ is the wheat kernel density, $m_{\text {air }}$ and $m_{\text {liquid }}$ the weight of the wheat kernel in air and liquid, respectively, and $\rho_{1}$ the density of the liquid. The liquid density was determined using a glass calibration weight of known density.

The liquids used were water, mixtures of water and ethanol (Fisher Scientific, Loughborough, UK), and xylene $\left(\mathrm{C}_{6} \mathrm{H}_{4}\left(\mathrm{CH}_{3}\right)_{2}\right.$, mixed isomers, also from Fisher). Xylene has a density of $0.86 \mathrm{~g} \mathrm{~cm}^{-3}$ and a surface tension of $31.23 \mathrm{mN} \mathrm{m}^{-1}$ at $30^{\circ} \mathrm{C}^{23}$, and is non-wetting of the wheat grains ${ }^{24}$. The liquid was maintained at $30^{\circ} \mathrm{C}$ when water or xylene was used, and at $40^{\circ} \mathrm{C}$ for water-ethanol solutions, using a jacketed beaker through which water was recirculated from a temperature-controlled water bath. Xylene is flammable and carcinogenic, so for safety the system was operated in a fume cupboard. Figure 2 shows a schematic of the double cup density meter and the temperature control system.

The above samples and methods were used to investigate the effect of measurement technique, wheat variety, size and moisture content on wheat kernel density determination.

\section{Effect of Measurement Method, Kernel Size and Wheat Variety on Density Measurement}

Wheat kernels from the two varieties, Hereward and Consort, were separated into twelve size fractions according to the thickness (third largest dimension) of the kernels using the Satake Rice Image Analyser (Model RIA-1A, Satake Corporation, Japan). The twelve size fractions comprised ten of $0.125 \mathrm{~mm}$ increments covering the 2$3.25 \mathrm{~mm}$ range, with one fraction of kernels of 3.25 $3.5 \mathrm{~mm}$, and the last fraction from $3.5-4.2 \mathrm{~mm}$. The moisture content was $9 \%$ (wet basis) for Hereward and $7 \%$ for Consort ${ }^{25}$. The density of kernels in each size fraction was measured using the Accupyc and the Precisa, using both water and xylene as the liquid for the latter technique. The Accupyc gave only average density measurements, while the Precisa allowed distributions of individual kernel densities to be determined. Three replicate measurements of average density were made using the Accupyc for each size fraction. Using the Precisa, 30 kernels from each size fraction were measured individually and the average density and standard deviation calculated.

\section{Effect of Liquid Surface Tension on Density Measurement of Wheat in the Precisa}

The effect of surface tension on density measurement in the Precisa was investigated by preparing five water-ethanol mixtures of different surface tensions, as shown in Table 1. Because the different mixture ratios have different densities, the Precisa was recalibrated for each solution.

For each wheat variety, 25 samples were prepared, each containing 10 wheat kernels of size $2.75-3 \mathrm{~mm}$. The moisture contents of these samples were $14.0 \%$ for Hereward and $13.8 \%$ for Consort. The average density of five replicate

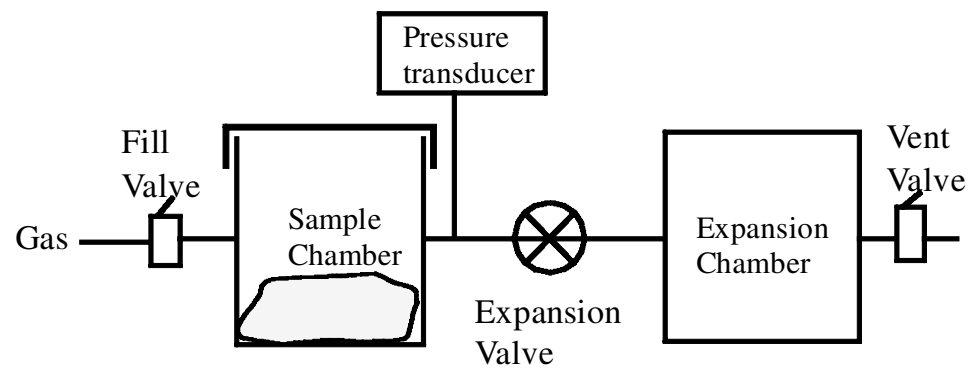

Figure 1. Principle of the Accupyc gas pycnometer. The sample chamber is pressurized, then the expansion valve opened to allow pressure equilibration with the expansion chamber. Knowing the volumes of the two chambers and the change in pressure, the volume of the sample can be calculated. 


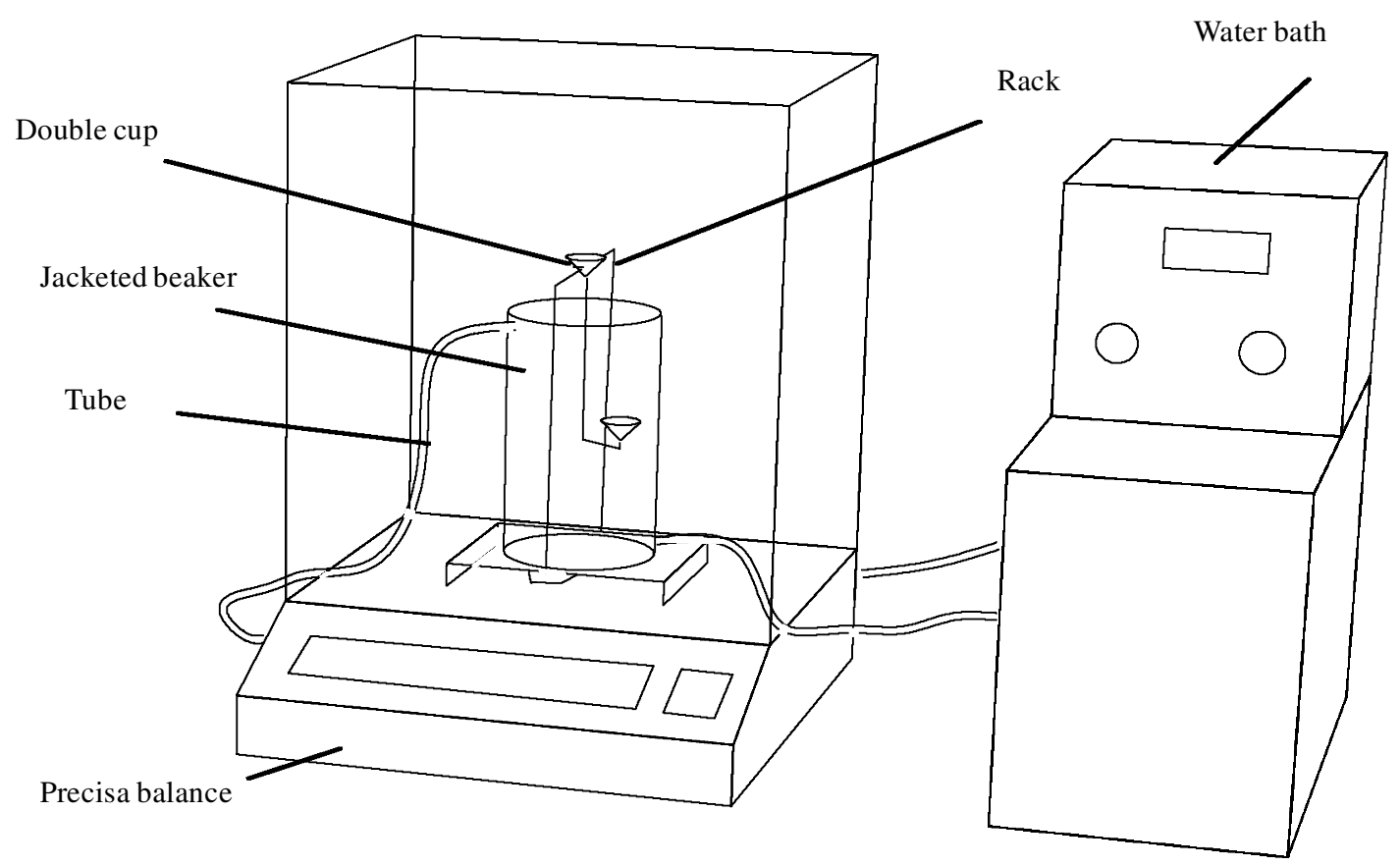

Figure 2. Schematic diagram of the Precisa balance and density determination kit.

Table 1. Surface tension and density of ethanol solutions at $40^{\circ} \mathrm{C}^{26}$.

\begin{tabular}{llllll}
\hline $\begin{array}{l}\text { Volume percentage } \\
\quad \text { of ethanol }(\%)\end{array}$ & 0 & 10 & 34 & 60 & 96 \\
$\begin{array}{l}\text { Surface tension }\left(\mathrm{mN} \mathrm{m}^{-1}\right) \\
\text { Liquid density }\left(\mathrm{g} \mathrm{cm}^{-3}\right)\end{array}$ & 09.56 & 48.25 & 31.58 & 26.18 & 21.38 \\
\hline
\end{tabular}

Table 2. Average ( \pm 1 standard deviation) of single kernel mass, moisture, diameter and hardness of Hereward and Consort wheat, measured using the Perten SKCS

\begin{tabular}{lcccc}
\hline $\begin{array}{l}\text { Parameter } \\
\text { Wheat variety }\end{array}$ & $\begin{array}{c}\text { Mass } \\
(\mathrm{mg})\end{array}$ & $\begin{array}{c}\text { Moisture } \\
(\%)\end{array}$ & $\begin{array}{c}\text { Diameter } \\
(\mathrm{mm})\end{array}$ & Hardness index \\
\hline Hereward & $48.4 \pm 12.1$ & $14.44 \pm 0.42$ & $3.03 \pm 0.53$ & $50.64 \pm 17.21$ \\
Consort & $45.6 \pm 13.5$ & $13.71 \pm 0.36$ & $2.81 \pm 0.59$ & $10.75 \pm 17.86$ \\
\hline
\end{tabular}

samples in each of the five solutions was measured using the Precisa.

\section{Effect of Moisture Content on the Kernel Density}

For this study, wheat kernels from each variety in the size range $2.875-3.0 \mathrm{~mm}$ were chosen. The samples were dried in an oven at $50^{\circ} \mathrm{C}$ for 120 hours, after which time the moisture had dropped to $5.1 \%$ for Hereward and $6.1 \%$ for Consort. Six samples were extracted for each wheat variety, and water added to five of them to obtain moisture contents covering the range $5-20 \%$. Samples were left to temper for 24 hours, then their moisture contents remeasured by an airoven method ${ }^{25}$.

The density of the kernels at each moisture content was measured using the Precisa, with xylene as the liquid. A tray made from wire mesh was used to hold 25-35 kernels, allowing the average density to be measured quickly. Five

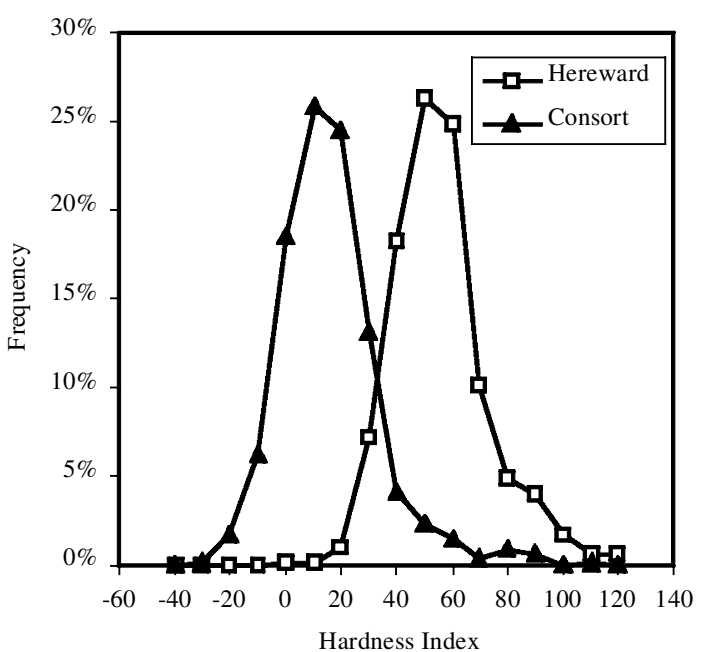

Figure 3. SKCS Hardness distributions for Hereward and Consort.

replicate measurements were made at each moisture content for each variety.

\section{RESULTS AND DISCUSSIONS}

\section{Wheat Characteristics}

Table 2 shows the average kernel size, mass, moisture and hardness determined for the two wheat varieties using the Perten SKCS. (The hardness index has no units; it is arbitrarily defined, and can even extend to negative values.) Clearly the Hereward wheat kernels are on average harder and slightly larger than the Consort. Figure 3 shows the distribution of single kernel hardness for the two varieties, showing broad, overlapping distributions. 


\section{Effect of Measurement Method, Kernel Size and Wheat Variety on Density Measurement}

Figure 4 shows the average density and the standard deviation of each size fraction for the two wheats, measured using the Accupyc gas pycnometer and the Precisa density kit with xylene and water. (Note that the error bars for the Precisa results are \pm 1 standard deviation of the population, not of the mean; hence they appear much larger than those of the Accupyc.) Clearly the Accupyc gave the highest average density values, while the xylene gave slightly lower values, and the water the lowest, lower than that obtained by the Accupyc by $6.2 \%$ for Hereward and $9.9 \%$ for Consort. This is almost certainly due to the surface tension of the liquids, which is higher for water $\left(69.56 \mathrm{mN} \mathrm{m}^{-1}\right.$ at $\left.40^{\circ} \mathrm{C}\right)$ than for the xylene $\left(31.23 \mathrm{mN} \mathrm{m}^{-1}\right)$. Figure 5 illustrates how surface tension would prevent liquid entering the crease of the kernel and pores on the surface, effectively increasing the apparent volume of the kernel and decreasing its measured density. Chasseray ${ }^{24}$ noted that air displacement methods give better results than liquid displacement methods.

From Figure 4, all three methods gave slightly higher density measurements for the hard wheat, Hereward, than for the Consort, in agreement with the suggestion of previous workers ${ }^{15,16}$ that hard wheats tend to have higher densities. For the Consort there was no effect of kernel size on density; the two parameters are independent, as confirmed by analysis of variance. The density of the Hereward samples as measured by the Accupyc also did not vary with size, but density measurement using the Precisa with water suggested that smaller kernels had lower densities. This too is almost certainly due to the effect of surface tension; the surface roughness or shape of the crease may well be slightly different in smaller kernels for this wheat variety. Table 3 summarizes the average density measured by the three methods for the two varieties.

From the data in Table 3, it can be seen that the differences in the measured density, and hence the effective kernel volume, given by the Accupyc and the Precisa with water are $7.1 \%$ for Hereward and $10.0 \%$ for Consort. These differences mean that there are pores and crevices on the kernel surfaces that are accessible to gas but not to water, and that these comprise up to $10 \%$ of the kernel volume.

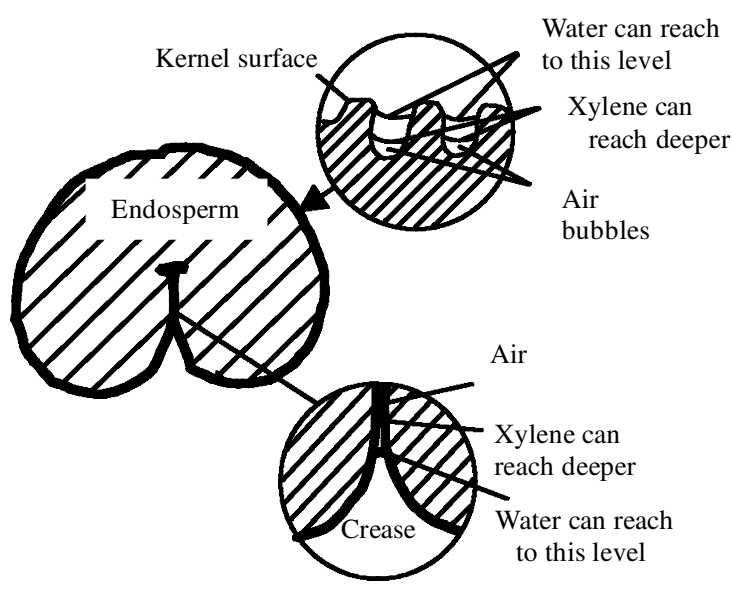

Figure 5. Schematic showing that the lower surface tension liquid (xylene) can penetrate further into the pores and crevices in the kernel surface than the higher surface tension liquid (water).

Table 3. Average kernel density ( \pm 1 standard deviation) for Hereward (hard) and Consort (soft) wheat measured by Accupyc gas pycnometer and by Precisa density kit with xylene and water.

\begin{tabular}{lcc}
\hline \multicolumn{1}{c}{$\begin{array}{c}\text { Variety } \\
\text { Method }\end{array}$} & Hereward & Consort \\
\hline Accupyc & $1.369 \pm 0.0032 \mathrm{~g} \mathrm{~cm}^{-3}$ & $1.345 \pm 0.0037 \mathrm{~g} \mathrm{~cm}^{-3}$ \\
Precisa with xylene & $1.331 \pm 0.0132 \mathrm{~g} \mathrm{~cm}^{-3}$ & $1.287 \pm 0.0125 \mathrm{~g} \mathrm{~cm}^{-3}$ \\
Precisa with water & $1.272 \pm 0.0316 \mathrm{~g} \mathrm{~cm}^{-3}$ & $1.210 \pm 0.0186 \mathrm{~g} \mathrm{~cm}^{-3}$ \\
\hline
\end{tabular}

This estimate is larger than that of Chang ${ }^{19}$, whose data suggest $2.3-5.1 \%$ of the kernel volume is accessible to gas, when the volume is determined by enclosing the kernel with wax. If xylene results are used, the air spaces accessible to gas are calculated to be $2.8 \%$ for Hereward and $4.3 \%$ for Consort, which are consistent with Chang's results.

While the Accupyc gives the most accurate result, i.e. that closest to the true density, it can only yield an average measurement, while the Precisa allows individual kernel densities to be measured. Figure 6 confirms the independence of kernel size and density by plotting the dry weight

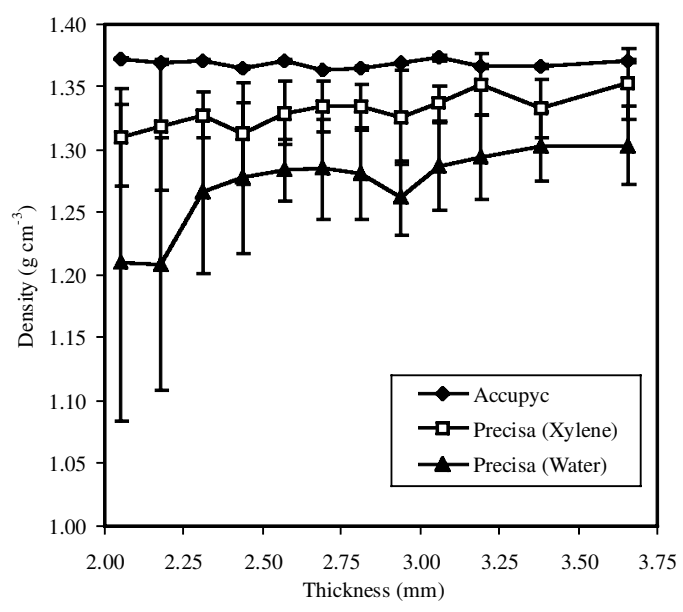

(a)

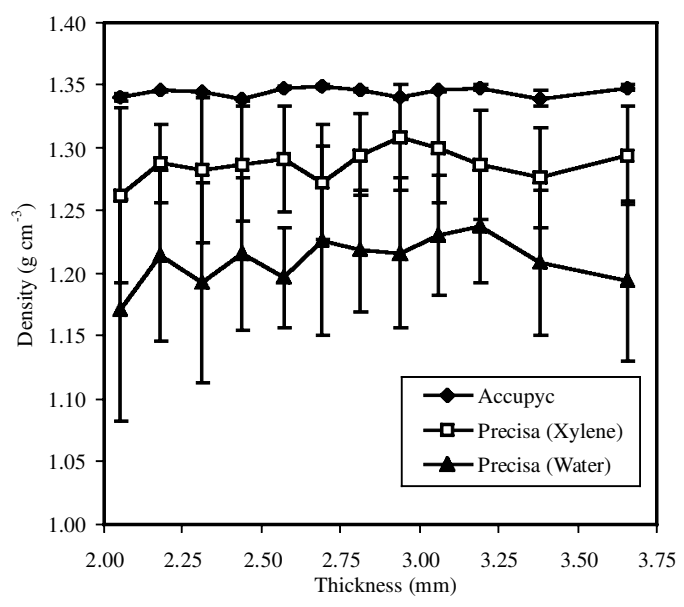

(b)

Figure 4. Densities of various size fractions measured by three different methods for (a) Hereward; and (b) Consort wheat kernels. 


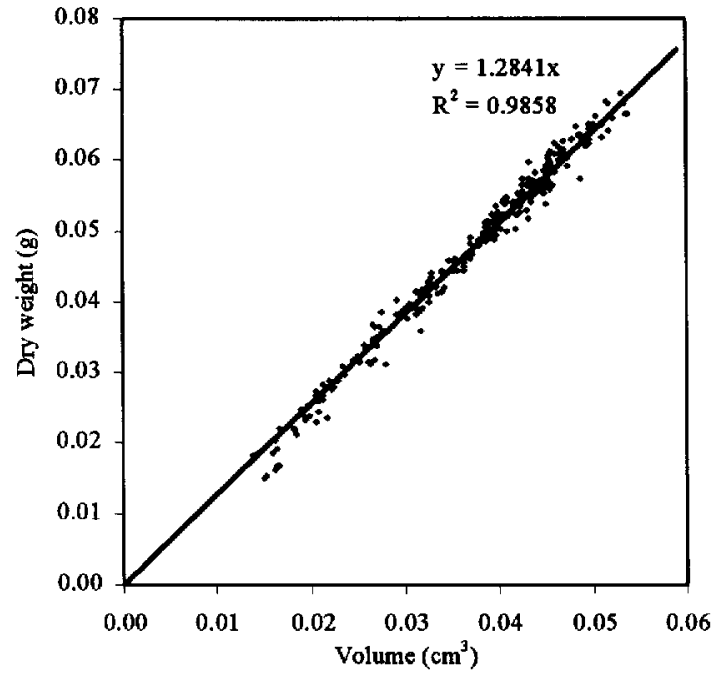

(a)

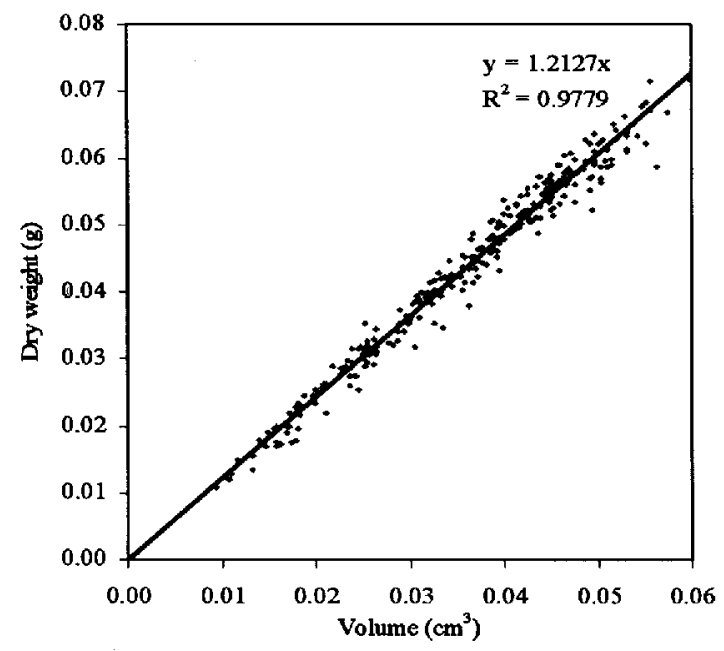

(c)

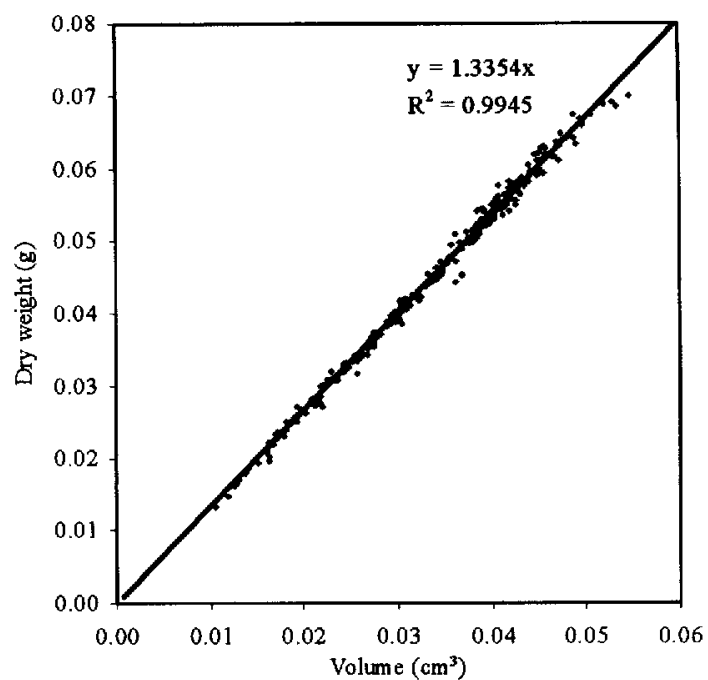

(b)

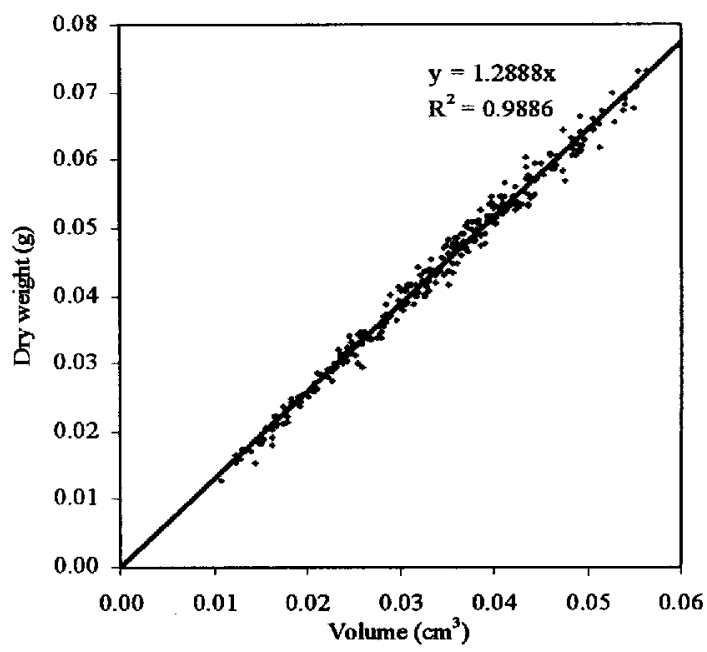

(d)

Figure 6. Dry weight versus kernel volume for (a) Hereward in water; (b) Hereward in xylene; (c) Consort in water; and (d) Consort in xylene.

versus the volume of individual kernels for each variety measured using xylene and water. The relationship is clearly linear with no hint of curvature, except for the smaller Hereward kernels. The slope of the line is equal to the average kernel density, which is larger for Hereward and larger when measured using xylene. (The slight difference compared with the average densities reported in Table 3 is due to the regression fit being constrained to pass through the origin.) The slightly better correlation coefficients given by xylene suggest that the lower surface tension not only gives greater accuracy but also greater precision, by reducing the variability in the measurement contributed by the variable surface porosity. Even greater accuracy could be achieved by using a liquid of even lower surface tension; for example, Abe et al. ${ }^{27}$ reported that a solution of xylene with surface tension of $10 \mathrm{mN} \mathrm{m}^{-1}$ could be prepared by the addition of suitable surfactants. However, ultimately a dry single kernel density meter is needed to achieve accuracy while retaining the benefit of measuring the density distribution.

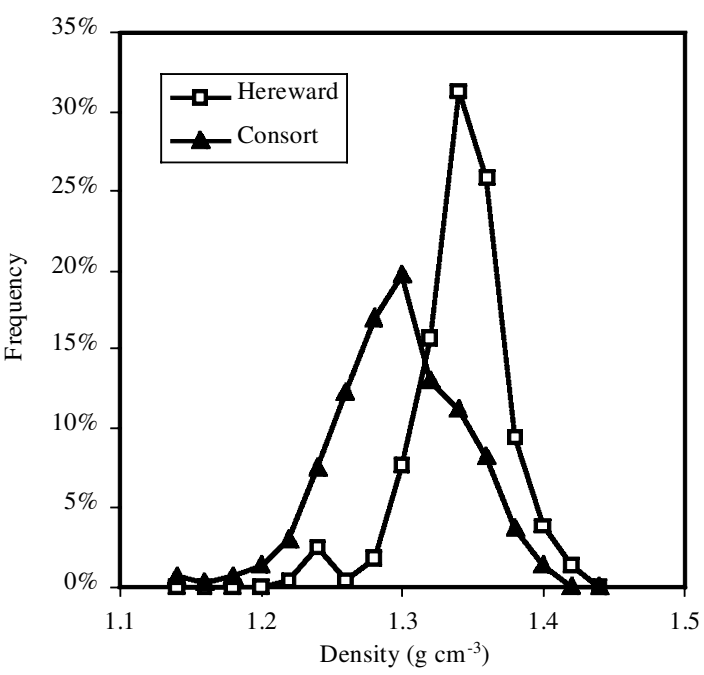

Figure 7. Density distributions of Hereward and Consort kernels, measured using the Precisa with xylene. 
The Precisa also allows the distribution of densities to be determined, as shown in Figure 7, which indicates again a lower average density for Consort, but also a slightly broader distribution of kernel densities, is agreement with the finding of Dobraszczyk et al. ${ }^{16}$. As wheat grains break individually, it is the distribution of densities that is needed, rather than an average value, if density is to be related to wheat breakage in a predictive sense.

\section{Effect of Liquid Surface Tension on Density Measurement of Wheat in the Precisa}

To investigate further the influence of the surface tension of the liquid on the density measurement, solutions of varying surface tension were prepared by mixing ethanol and water as described above, and used to measure wheat kernel densities using the Precisa. Figure 8 shows the density values obtained for the two wheats as a function of surface tension. For comparison, the measured densities of two wheat varieties by Accupyc are also included in the graph; these are equivalent to measuring with a liquid of zero surface tension. Clearly as surface tension reduced, the measured density increased to a value approaching the average density measured by the Accupyc. This supports the hypothesis that the surface tension of the liquid is the reason for the lower density measurements.

\section{Effect of Moisture Content on Wheat Kernel Density}

Samples of different moisture content were prepared as described above, and their density measured using the Precisa with xylene. Figure 9 shows the measurement results of the two wheat varieties at various moisture contents. It can be seen that in the range of moisture contents from $5.13 \%$ to $19.3 \%$ for Hereward and from $6.12 \%$ to $19.6 \%$ for Consort, the kernel density reduced as the moisture content increased. This supports the findings of Sharp ${ }^{17}$ and Peters and $\mathrm{Katz}^{18}$. A $1 \%$ increase in moisture gave a decrease in density of approximately $0.3 \%$.

If the decrease in density is simply due to the contribution to the kernel mass and volume of water (which has a lower density than starch $\left(1.5 \mathrm{~g} \mathrm{~cm}^{3}\right)$ and protein $\left(1.4 \mathrm{~g} \mathrm{~cm}^{3}\right)^{28}$, the

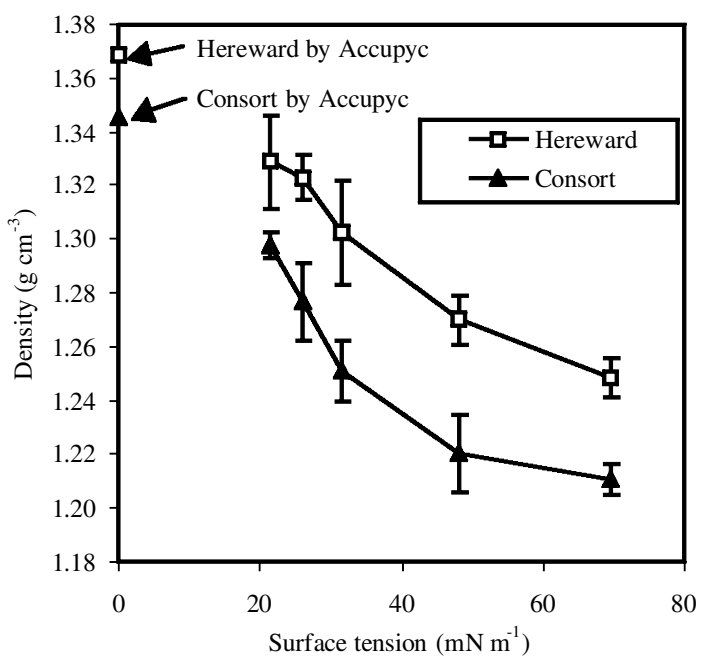

Figure 8 . The effect of surface tension of the liquid on the measured kernel density.

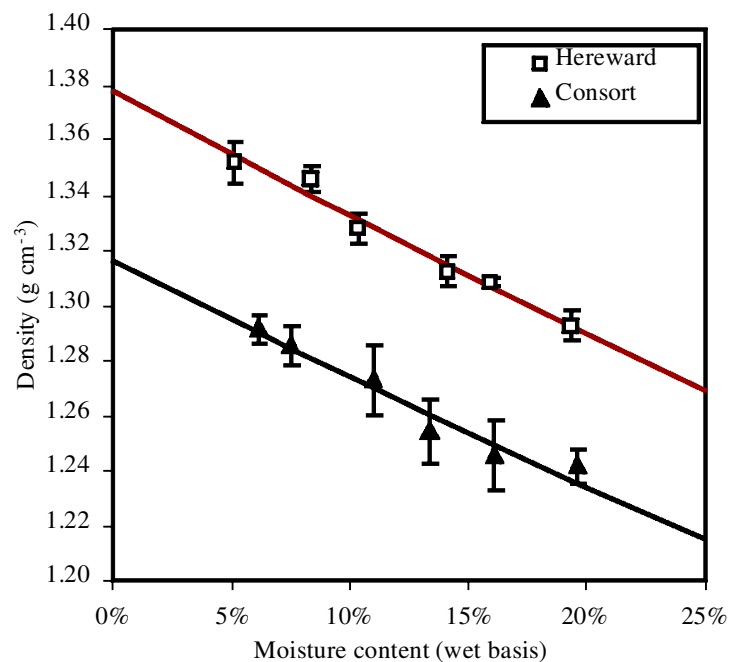

Figure 9. The effect of moisture content on the kernel density.

major wheat endosperm components), then the density can be related to the mass fraction, $m$, of water by

$$
\rho=\frac{\rho_{0} \rho_{l}}{(1-m) \rho_{l}+m \rho_{0}}
$$

where $\rho_{0}$ is the density of the kernel at $0 \%$ moisture, and $\rho_{l}$ is the density of water. Inverting equation (4) allows it to be linearized such that $\rho_{0}$ and $\rho_{l}$ can be evaluated:

$$
\frac{1}{\rho}=\frac{1}{\rho_{0}}+m\left(\frac{1}{\rho_{l}}-\frac{1}{\rho_{0}}\right)
$$

Using this procedure, the values of $\rho_{0}$ were found to be 1.378 and $1.316 \mathrm{~g} \mathrm{~cm}^{-3}$ for Hereward and Consort, respectively. These are lower than might be expected based on the density of the kernel components, starch, protein and bran, due to the porosity of the kernels, and suggest air contents of about 7 and $11 \%$ for the Hereward and Consort, respectively. These values are slightly higher than the 3.6-7\% reported by Chang ${ }^{19}$, but support the suggestion that lower densities of soft wheats are due to higher air contents. The values of $\rho_{l}$ were found to be 1.026 and $0.987 \mathrm{~g} \mathrm{~cm}^{-3}$, respectively, for the two varieties, which are within experimental error of the expected value of $1 \mathrm{~g} \mathrm{~cm}^{-3}$. Figure 9 plots the slightly curved line given by equation (4) for each variety using these fitted coefficients. Although equation (4) fits the experimental data well by considering only the moisture content, it must be acknowledged that some other components of wheat kernels may swell or shrink with the change of moisture content, and thus may also contribute to the density change. Nevertheless, it may be fairly concluded that the lower density on increasing moisture content is primarily due to the lower density of water compared with that of the moisture-free kernel.

\section{CONCLUSIONS}

Wheat grains break independently during roller milling, with the breakage of each kernel depending on its own physico-chemical characteristics such as size, hardness and density. The density of individual wheat kernels is independent of kernel size, and appears to be greater and more 
uniform for hard wheat varieties compared with soft varieties, supporting the findings of previous workers ${ }^{16}$. Increasing moisture content decreases kernel density due to the lower density of water compared with the major wheat components. Kernel density is measured most accurately using dry techniques such as the Accupyc gas pycnometer; density measurement using liquids is affected by bubbles and air pockets trapped on the surface of the grain, in the brush hairs and in the crease. The Accupyc, however, does not allow individual kernel densities, and the distribution of densities, to be measured, whereas the Precisa density determination kit does. A single kernel density meter based on a dry technique would allow accurate determination of density distributions, for use in models of wheat breakage during roller milling.

\section{REFERENCES}

1. Kent, N. L. and Evers, A. D., 1994, Ken's Technology of Cereals, 4th Ed., (Elsevier Science, Oxford, UK).

2. Satake, R. S., 1990, Debranning process is new approach in wheat milling, World Grain 8(b) (28): 30-32.

3. Forder, D. E., 1997, Flour milling process for the 21st Century, in: Cereals: Novel Uses and Processes, Campbell, G. M., Webb, C. and McKee, S. L. (Eds), (Plenum Press, New York), 257-264.

4. Bunn, P. J., Campbell, G. M. and Hook, S. C. W., 1999, Prediction of particle size distribution arising from First Break milling of wheat mixtures, Proc of Process Engineering of Cereal Products Workshop, Montpellier, France, 8th October 1999, (ICC, Austria).

5. Campbell, G. M. and Webb, C., On predicting roller milling performance. II. The breakage function, Powder Technol (in press).

6. Martin, C., Rousser, R. and Brabec, D. L., 1993, Development of a single-kernel wheat characterization system, Trans ASAE, 36: 13991404.

7. Evers, A. D., 1996, New opportunities in wheat grading, 26th Nordic Cereal Congress.

8. Satumbaga, R., Martin, C., Eustace, D. and Deyoe, C. W., 1995 , Relationship of physical and milling properties of hard red winter wheat using the single kernel wheat characterization system, Assoc Operative Millers Bull, January: 6487-6496.

9. Gaines, C. S., Finney, P. F., Fleege, L. M. and Andrews, L. C., 1996, Predicting a hardness measurement using the single-kernel characterization system, Cereal Chem, 73: 278-283.

10. Osborne, B. G., Kotwal, Z., Blakeney, A. B., O'Brien, L., Shah, S. and Fearn, T., 1997, Application of the single-kernel characterization system to wheat receiving testing and quality prediction, Cereal Chem, 74: 467-470.

11. Deyoe, C., Chen, Y., Reddy, P. V., McCluskey, P., Gwirtz, J. and Eustace, D., 1998, Utilization of the SKWCS information in hard red winter wheat surveys for quality evaluations, Assoc of Operative Millers Bulletin, July: 7131-7140.
12. Pomeranz, Y., 1988, Wheat: Chemistry and Technology, Vol 1, 3rd Ed., (AACC).

13. Glenn, G. M., Younce, F. L. and Pitts, M. J., 1991, Fundamental physical properties characterizing the hardness of wheat endosperm, J Cereal Sci, 13: 179-194.

14. Dobraszczyk, B. J., 1994, Fracture mechanics of vitreous and mealy wheat endosperm, J Cereal Sci, 19: 273-282.

15. Pomeranz, Y. and Mattern, P. J., 1988, Genotype and genotype $x$ environmental interaction effects on hardness estimates in winter wheat, Cereal Food World, 33: 371-374.

16. Dobraszczyk, B. J., Whitworth, M. B., Vincent, J. F. V. and Khan, A. A., Single kernel wheat hardness and fracture properties in relation to density and the modelling of fracture in wheat endosperm, J Cereal Sci (in press).

17. Sharp, P. F., 1927, Wheat and flour studies IX: Density of wheat as influenced by freezing, stage of development, and moisture content, Cereal Chem, 4: 15-46.

18. Peters, W. R. and Katz, R., 1962, Using a density gradient column to determine wheat density, Cereal Chem, 39: 487-494.

19. Chang, C. S., 1988, Measuring density and porosity of grain kernels using a gas pycnometer, Cereal Chem, 65: 13-15.

20. Martin, C., Cherrman, T. J., Loughin, T. and Oentong, S., 1998, Micropycnometer measurement of single-kernel density of healthy, sprouted and scab-damaged wheats, Cereal Chem, 75: 177-180.

21. Micromeritics, 1987, Instruction Manual of Multivolume Pycnometer 1305, (Micromeritics Instrument Corporation, Norcross, GA, USA).

22. Webb, P. A. and Orr, C., 1997, Analytical Methods in Fine Particle Technology, (Micromeritics Instrument Corporation, Norcross, GA, USA).

23. Lange, N. A., 1985, Lange's Handbook of Chemistry, 13th Ed., (McGraw-Hill, New York, USA).

24. Chasseray, P., 1994, Physical characteristics of grains and their byproducts, Primary Cereal Processing, Godon, B. and Willm, C. (Eds), (VCH Publishers, Inc., New York), 85-141.

25. AACC Method 44-15A, 1995, (AACC, Minnesota, USA).

26. Weast, R. C. and Astle, M. J., 1979, CRC Handbook of Chemistry and Physics, 60th Ed. (CRC Press Inc., Florida, USA).

27. Abe, M., Morikawa, K. and Ogino, K., 1992, Reduction of surface tension of pure m-xylene by novel fluorinated surfactants, Langmuir, 8: 763-764.

28. Lewis, M. J., 1996, Physical Properties of Foods and Food Processing Systems (Woodhead Publishing, Cambridge, UK).

\section{ADDRESS}

Correspondence concerning this paper should be addressed to Dr G. M. Campbell, Satake Centre for Grain Process Engineering, Department of Chemical Engineering, UMIST, Manchester, M60 1QD, UK. E-mail: g.campbell@umist.ac.uk

The manuscript was received 10 October 2000 and accepted for publication after revision 5 December 2000. 